\title{
WATER TREATMENT PLANT SLUDGE CHARACTERIZATION, RECOVERY OF COAGULANT AND ITS REUSE
}

\author{
Alok Suman ${ }^{1}$, Kafeel Ahmad ${ }^{2}$, InamulHaq ${ }^{3}$ \\ ${ }^{l}$ Research Scholar, Department of Civil Engineering \\ ${ }^{2}$ Prof. Department of Civil Engineering \\ ${ }^{3}$ UGC Scholar in Residence Department of Civil Engineering
}

\begin{abstract}
In the purification of water, conventional coagulants are mostly used, which produces large quantity of sludge. Therefore, the possibilities of sludge volume reduction, recovery of chemicals and their reuse as coagulant in the treatment of water and wastewater need to be explore. The objective of the study is to determine the physio-chemical characteristics of sludge obtained from water treatment plant and to investigate the regeneration of chemicals from WTS as coagulant for its re-use in wastewater treatment plants. WTS was collected from the Delhi Jal Board's water treatment plant (Chandrawal Water Works, New Delhi) which uses poly aluminum chloride (PAC) as coagulant in water treatment plant. The physio-chemical property of water treatment sludge was determined by using advance techniques such as Scanning Electron Microscope (SEM), Energy-Dispersive $X$-Ray Diffraction (ED-XRD), Fourier Transform Infrared Spectroscopy (FTIR). The sludge characteristic showed that it contains maximum amount of $\mathrm{SiO}_{2}$ at $67.75 \%$.The other oxides observed by ED-XRD method in sludge samples were $\mathrm{Al}_{2} \mathrm{O}_{3}(16.76 \%)$, $\mathrm{Fe}_{2} \mathrm{O}_{3}(5.52 \%)$ and $\mathrm{MgO}(3.33 \%)$. The analysis results of WTS also showed the presence of different trace metals such as $\mathrm{Ni}$ (21.97 $\mathrm{mg} / \mathrm{kg}), C u(38.31 \mathrm{mg} / \mathrm{kg}), \mathrm{Zn}(83.08 \mathrm{mg} / \mathrm{kg}), \mathrm{As}(18.00 \mathrm{mg} / \mathrm{kg}), \mathrm{Rb}(136.26 \mathrm{mg} / \mathrm{kg}), \quad \mathrm{Sr}(68.41 \mathrm{mg} / \mathrm{kg}), \quad B a(485.94$ $\mathrm{mg} / \mathrm{kg})$, and $\mathrm{Pb}(24.00 \mathrm{mg} / \mathrm{kg})$ determined by ED -XRD. The WTS collected was acidified with different normality of sulfuric acid from $1 \mathrm{~N}$ to $4 \mathrm{~N}$ to produce chemical as a regenerated coagulant. The sludge acidified by $3 \mathrm{~N}_{2} \mathrm{SO}_{4}$ was found to be an optimum condition for regeneration of coagulant. The regenerated coagulant of relatively high dose of $25 \mathrm{ml}$ solution with $3 \mathrm{~N}$ sludge acidification, when used to treat liter of synthetic dairy wastewater, produced better turbidity removal efficiency found at about 94\%. Thus, regenerated coagulant has the potential to substitute the conventional coagulant used in the water purification. This approach provides reuse potential of WTS and thus minimizes disposal cost, environmental damage, and health risk. This strategy of sludge management would achieve the economic, social, and environmental sustainability.
\end{abstract}

Keywords - coagulation-flocculation, Water Treatment, Sludge, Regenerated coagulant, SEM, ED-XRD, FTIR, XRD,

\section{INTRODUCTION}

In the purification of surface water, coagulation-flocculation process is mostly used for the removal of turbidity and other impurities. A large quantity of water treatment sludge (WTS) is generated which is presently being disposed of indiscriminately particularly in the developing countries. Such practices cause contamination of surface and groundwater resources. This is a serious problem requiring attention to adopt a sound environmental management for waste / sludge disposal to minimizes adverse impact on environment and socio-economic conditions arising due to unsystematic disposal. A sustainable sludge management, therefore, requires possibility of minimizing sludge generation or whatever generated is reused, and recycled. Such strategy must be explored for recovery of chemicals as by- products from WTS which can be re-used in the treatment of water and wastewater.

Coagulants based on Aluminum salts are commonly used for coagulation purposes. WTS contains considerable portions of aluminum hydroxide precipitate. The sludge has been utilized for many constructive purposes. Application of
WTS has been used for water and wastewater treatment processes. Lowest recovery of Aluminum from WTS was achieved at $\mathrm{pH} 1$ to 3 and maximum recovery at $\mathrm{pH} 2.5$. It fund that at maximum $\mathrm{pH}$ of 2.5 , the recovery of aluminum salt from the sludge, produced from the river water treatment plant, was max. It was suggested that the coagulant recovery from water treatment sludge is depended on different $\mathrm{pH}$ in coagulation process and advised coagulation to be carried out within $\mathrm{pH}$ range 6.5 to 8.5 and recovery of chemicals from sludge as regenerated coagulant in the $\mathrm{pH}$ range of $\mathrm{pH} 1.5$ to 2.5. To obtain lowest $\mathrm{pH} 1.5$, highly alkaline sludge is required whereas a typical coagulation process take place at optimal $\mathrm{pH}$ conditions $(\mathrm{pH}$ $6.6)$

WTS quality generally depend on the quality of raw water, the treatment technology and chemical used as coagulant in coagulation process. Generally, the groundwater having stable quality produce lower amount of sludge. However, in case of surface water treatment, it has been observed a wide variation in waste generation (sludge) such as quality and quantity due to variation in the raw water quality as well as quantity of coagulant required in the treatment processes. 
The water treatment sludge (WTS) produced in the water treatment plants constitutes organic and inorganic matter. The physical, chemical and biological characteristics of WTS generally varies. The poly- disperse suspension with a wide range of rough disperse or even colloidal particles are present in the WTS. The turbidity in terms of dispersed or colloidal particles present in raw water are agglomerated and settled down by the coagulants. Therefore, chemicals used in coagulation process frequently create a considerable part of the sludge. The common used coagulants are aluminum salts ferric salts, and ferrous iron salts. The WTS generated also consists of changeable nature and concentrations of organics, inorganics, suspended solids, coagulant products and trace elements.

The composition of WTS states that oxide of silica was the major constituent. In the water treatment, mostly Al based or Fe based composition has been found in WTS while physicochemical analysis which contains heavy metalsin trace. The variation in presence of oxide percentage also observed due to variation in raw water quality, composition of coagulants, water treatment technology and treated water quality. In general, $\mathrm{SiO}_{2}$ foundsasmajor portion of the sludge and followed by $\mathrm{Al}_{2} \mathrm{O}_{3}$ and $\mathrm{Fe}_{2} \mathrm{O}_{3}$. Other oxides such as $\mathrm{CaO}, \mathrm{MgO}, \mathrm{Na}_{2} \mathrm{O}, \mathrm{K}_{2} \mathrm{O}, \mathrm{P}_{2} \mathrm{O}_{5}$ and $\mathrm{TiO}_{2}$ were found in small percentage. The percentage metals were carried along with surface water and/or as impurities in the coagulants which get concentrated in sludge during the treatment process. Present study was undertaken to (i) determine the physiochemical characteristics of water treatment sludge collected from a water treatment plant, (ii) the WTS was used to investigate the optimum condition for maximum recovery or regeneration of chemicals as coagulant for reuse, and (iii) the regenerated coagulants was reused to examine the treatability of dairy wastewater for removal of turbidity- a case of sustainable sludge management.

\section{MATERIALS AND METHOD}

In present the study, WTS was collected from the Delhi Jal Board's water treatment plant. The name of the plant is Chandrawal Water Treatment Plant located in west Delhi which uses poly aluminum chloride (PAC) as coagulant. The physio-chemical property of water treatment sludge (WTS) was investigated by using Scanning Electron Microscope (SEM), Energy-Dispersive X-Ray Diffraction (ED-XRD), Fourier Transform Infrared Spectroscopy (FTIR), and X-Ray Powder Diffraction (XRD) methods.

The chemical composition of the sludge surface morphology was studied by scanning electron microscope (SEM) using Jeol model JSM 6510 LV equipment coupled with energy dispersive spectroscopy. The elemental analysis of water treatment sludge was carried out using ED-XRF setup involving a low power $(100 \mathrm{~W})$ tungsten anode X-ray tube (Kevex, $50 \mathrm{kV}, 2.0 \mathrm{~mA}$, water cooled) as source of excitation. The X-ray tube was operated at $35 \mathrm{kV}$ and 1.7 $\mathrm{mA}$. The Fourier transform infrared (FTIR) spectroscopic analysis of sample was carried out using VERTEX 70V instrument. FTIR scans were performed in $\mathrm{KBr}$ chamber at frequencies from 4000 to 400 per $\mathrm{cm}$ and spectral resolution of 4 per $\mathrm{cm}$. X-ray powder diffraction (XRD) was used for rapid phase identification of a crystalline material.

\subsection{Wastewater Preparation, Sludge Collection, and}

\section{their Characteristics}

For the preparation of Synthetic dairy wastewater (SDW), $7 \mathrm{ml}$ milk (full creammanufactured by Mother Dairy Fruits and Vegetable Ltd.) in one-liter distilled water and added onegram of kaolin $\left(\mathrm{H}_{2} \mathrm{Al}_{2} \mathrm{Si}_{2} \mathrm{O} \quad 8 \mathrm{H}_{2} \mathrm{O}\right)$ (laboratory Grade) powder and mixed to get a uniform solution. For the experimental works, SDW were prepared freshly whenever required to kept composition constant during study. SDW was prepared as per the standard methods. The SDW sample was analyzed for $\mathrm{pH}$, colloidal suspension removal in terms of turbidity, and other parameters as per the prescribed standard method of APHA

\subsection{Recovery or Regeneration of Coagulant from} Water Treatment Sludge (WTS)

The WTS collected was acidified with different normality of $\mathrm{H}_{2} \mathrm{SO}_{4}$ at $1.0 \mathrm{~N}$ to $4 \mathrm{~N}$ (interval of $0.5 \mathrm{~N}$ ) at a ratio of 0.02 $\mathrm{ml} \mathrm{H}_{2} \mathrm{SO}_{4} / \mathrm{ml}$ of sludge i.e. for the experimental purpose $100 \mathrm{ml}$ sludge was mixed with $2 \mathrm{ml} \mathrm{H}_{2} \mathrm{SO}_{4}$ of different normality. A varying conc. of product in solution as regenerated coagulant are produced with varying volume from $5 \mathrm{ml}$ to $30 \mathrm{ml}$ and normality and the same solution used to treat 1liter SDW for its turbidity removal.

\subsection{Performance Evaluation}

The efficiency performance of regenerated coagulant prepared in the laboratory has been evaluated for removal of colloidal suspension from synthetic dairy wastewater. Jar tests have been performed to simulate a conventional coagulation/ flocculation process. $1000 \mathrm{ml} \mathrm{SDW} \mathrm{sample} \mathrm{was}$ placed in a standard jar test apparatus. The variable dosage of regenerated coagulant of different normality was added in six Jars then a flash mixing of $2 \mathrm{~min}$. is provided to achieve the coagulation process followed by slow mixing for $30 \mathrm{~min}$. to flocculate the colloidal suspension during flocculation process. Thereafter, jars were kept undisturbed forabout 20 $-25 \mathrm{~min}$. to settle down the flocs and then supernatants are taken for determining the extent of turbidity removal. The batch experiments have been carried out at neutral $\mathrm{pH}$ condition.

\section{RESULTS AND DISCUSSION}

\subsection{SDW Characteristics}

Analysis of SDW water was carried out which showed it is a little acidic in the range of $\mathrm{pH}$ of 6.2-6.8 but higher in COD at $1250 \mathrm{mg} / \mathrm{l}$. the presence of colloidal suspension in terms of turbidity was $372 \mathrm{NTU}$ and TSS wasmeasured $348 \mathrm{mg} / \mathrm{l}$, with TDS at $1187 \mathrm{mg} / \mathrm{L}$. The SDW contains total solids at about $1535 \mathrm{mg} / \mathrm{l}$. 
The experimental observation showed thathigher coagulant dose was found to settle down the colloidal suspension. Similar observations were observed by other which suggested that a higher dose of different coagulants were used for treatment of water. To avoid such problems i.e. the use of higher dose of coagulant, kaolin powder was added to the SDW to make the solution uniform and lower the requirement of coagulant dose. This may help increased adsorption of colloids present in water on the large surface area of kaolin particles.

\subsection{WTS Chemical Characteristics or Composition}

XRD analysis of WTS was carried out for chemical composition as shown in Table 1 and Fig. No 1.The presence of $\mathrm{SiO}_{2}$ and $\mathrm{Al}_{2} \mathrm{O}_{3}$ in WTS were found to be present at $67.75 \%$ and $16.76 \%$ as a major constituent. The other oxides including $\mathrm{Fe}_{2} \mathrm{O}_{3}$ were in small quantity as shown in Table 1.Thepoly- aluminum chloride (PAC) is used in the water treatment plant, the WTS contains the higher percentage of aluminum. The oxides of silica, iron and others shown in XRD (Table 1, Fig No 1) are due to the impurities present in raw water and conventional coagulant used in raw water purification. The acidification of WTS regenerated aluminum and iron which acts as coagulant for its reuse in the treatment of synthetic dairy wastewater. The trace element analysis of WTS as shown in Table 1 was carried by ED -XRD These metals along with other oxides were present in raw water and conventional coagulate as impurities, and get accumulated in WTS. These heavy metals contaminate environment and cause risk to public health if it is not properly utilized or disposed. This is because many metals exceed the regulatory requirement of waste disposal notified by the ministry of Environment Govt. of India.

Table 1: Composition of WTS with trace elements

\begin{tabular}{|l|l|l|l|}
\hline Composition & \% W/W & Elements & mg/kg \\
\hline $\mathrm{SiO}_{2}$ & 67.75 & $\mathrm{Ni}$ & 21.97 \\
\hline $\mathrm{Al}_{2} \mathrm{O}_{3}$ & 16.76 & $\mathrm{Cu}$ & 38.31 \\
\hline $\mathrm{Fe}_{2} \mathrm{O}_{3}$ & 5.52 & $\mathrm{Zn}$ & 83.08 \\
\hline $\mathrm{MgO}$ & 3.33 & $\mathrm{Ga}$ & 13.48 \\
\hline $\mathrm{K}_{2} \mathrm{O}$ & 3.03 & $\mathrm{As}$ & 18.00 \\
\hline $\mathrm{CaO}$ & 2.37 & $\mathrm{Rb}$ & 136.26 \\
\hline $\mathrm{TiO}_{2}$ & 0.51 & $\mathrm{Sr}$ & 68.41 \\
\hline $\mathrm{MnO}$ & 0.09 & $\mathrm{Ba}$ & 485.94 \\
\hline $\mathrm{Cl}$ & 0.30 & $\mathrm{~Pb}$ & 24.00 \\
\hline
\end{tabular}

\subsection{Physico-Chemical Characterization}

(i) There is no sharp characteristic diffraction peaks was observed during the X-ray diffraction (XRD) analysis (Fig No 1) of sludge showed, it showing thepoorly ordered particles, having no distinct shape or form and suggesting that the crystalline $\mathrm{Al}(\mathrm{OH}) 3$ phase is absent within alum sludge.

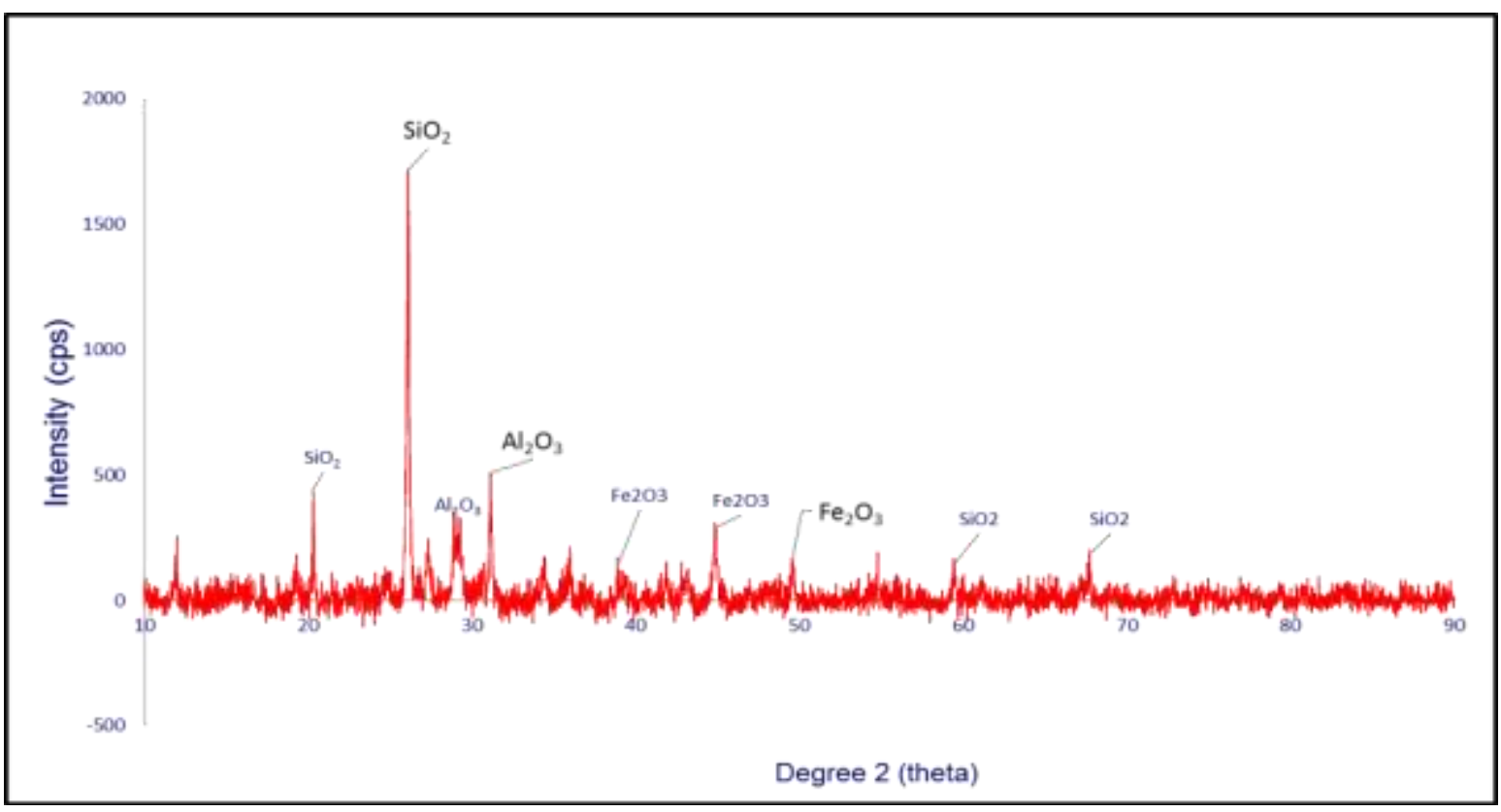

Fig 1: XRD analysis pattern of WTS

This gives an idea that alum sludge is amorphous in nature, silica $\left(\mathrm{SiO}_{2}\right)$ is one ofthe major crystalline phase present sludge. Similar findings also exhibited that silica $\left(\mathrm{SiO}_{2}\right)$ was the major crystalline solids recognized in numerous XRD analyses. The pure aluminum hydroxide as found by others exhibited a regular crystalline structure (ii) while scanning electron microscope (SEM) of WTS as shown in Fig No 2 that there is no definite crystalline appearance was observed on surface of the sludge and therefore the sludge parade the amorphous nature. 


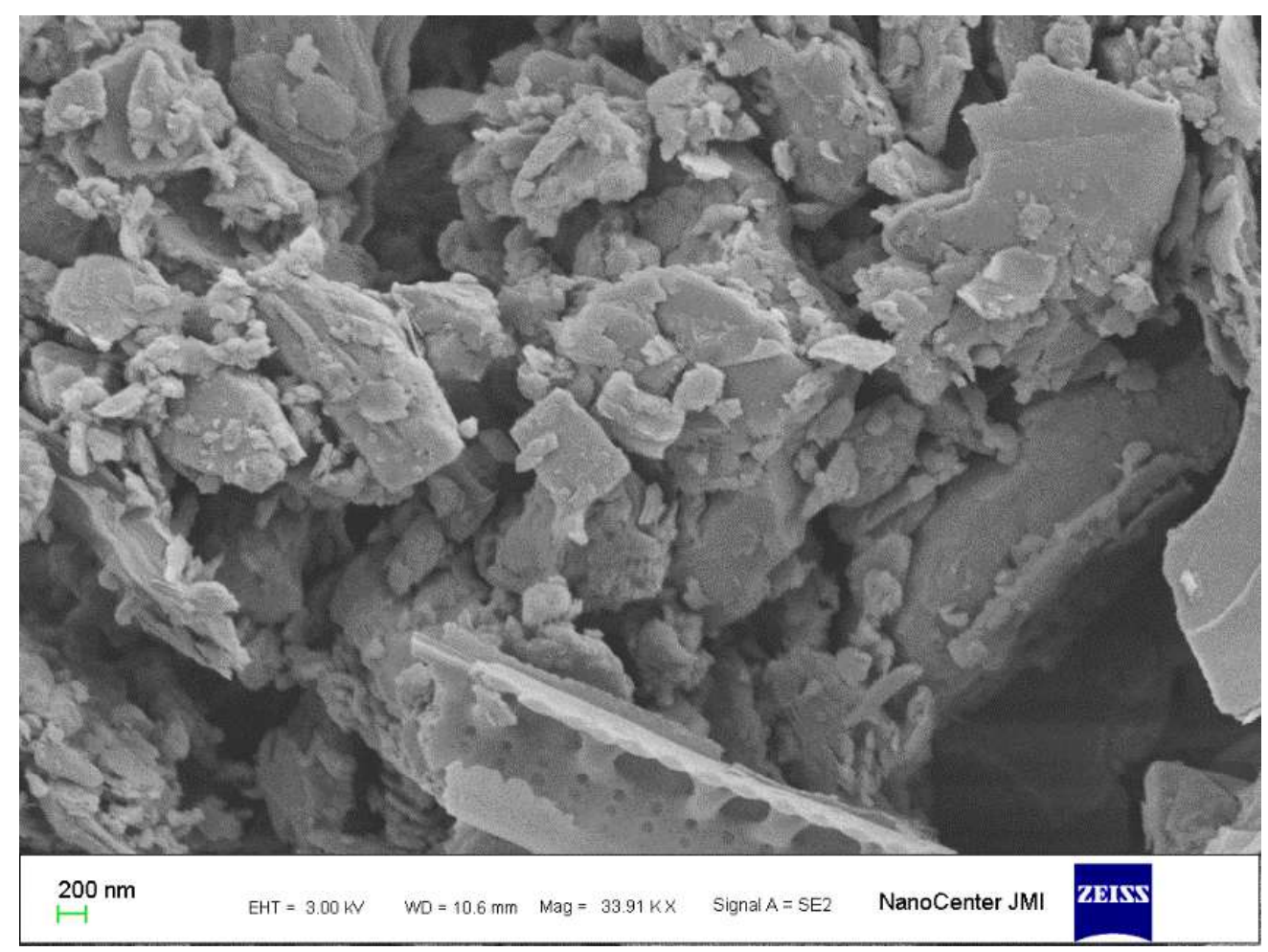

Fig 2: SEM micrograph of WTS at $200 \mathrm{~nm}$ distance and Magnification 33.91 KX.

Such observations were made in others which pointed that the sludge surface is highly porous structure having total micro-pore volumes in case of $\mathrm{Al}$ and Fe WTS were 0.042 and $0.012 \mathrm{~cm} 3 / \mathrm{g}$ respectively. The amorphous and porous nature of $\mathrm{Al}$ and $\mathrm{Fe}$ hydroxides makes the sludge surface sites more adsorptive in nature for majority of anions.
(iii)The FTIR Spectra of WTS collected for the recovery of coagulant for reuse in wastewater treatment, is shown in Fig No 3.

FTIR Spectra of WTS

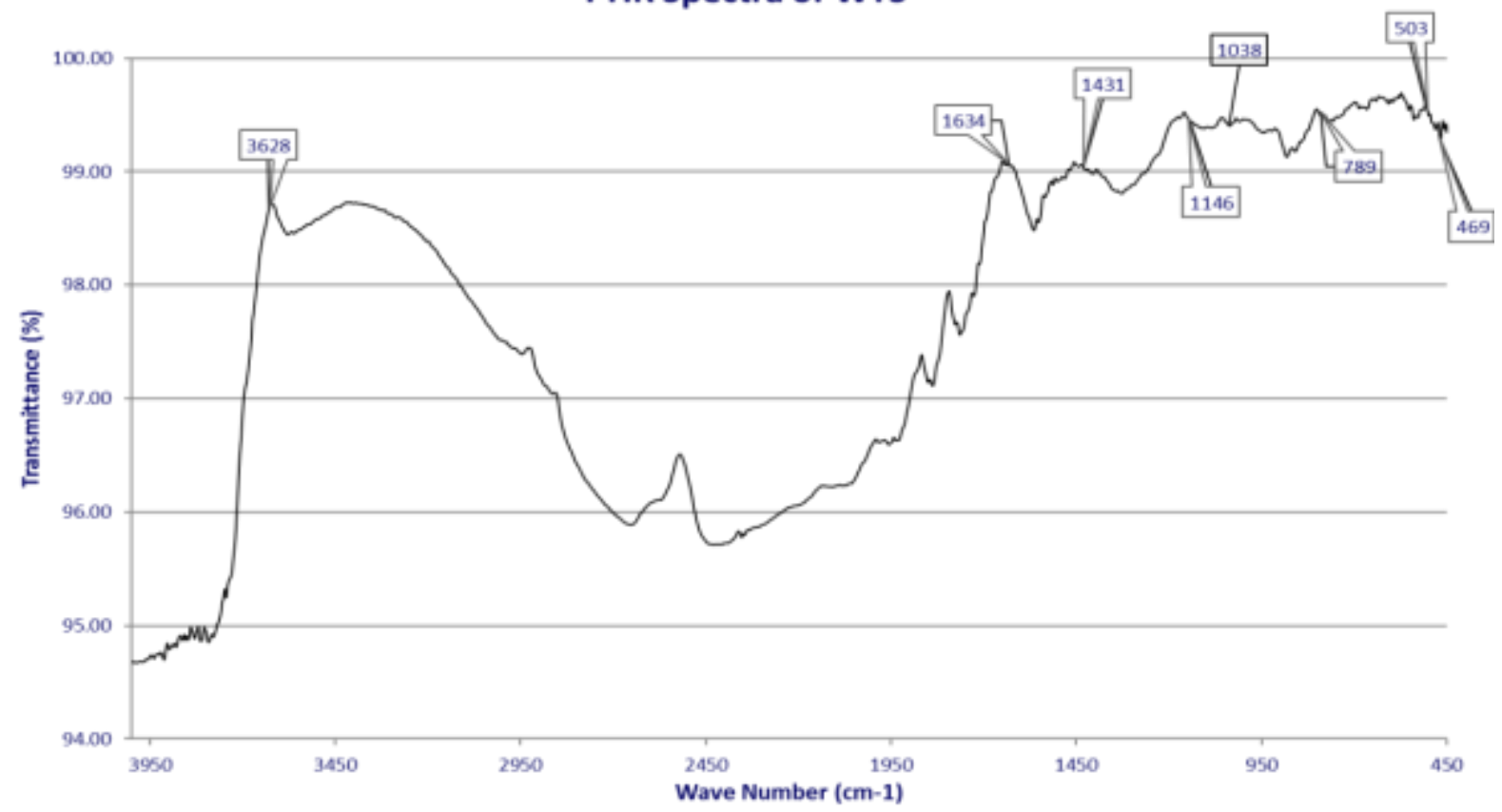

Fig 3: FTIR Spectra of WTS 
The bonded $\mathrm{O}-\mathrm{H}$ stretching vibration can be detected between 3650 and $3200 \mathrm{~cm}^{-1}$ (anti symmetric and symmetric $\mathrm{O}-\mathrm{H}$ stretching mode) and bending vibrations due to the $\mathrm{H}-\mathrm{O}-\mathrm{H}$ are between 1650 and $1600 \mathrm{~cm}^{-1}$ Such observations in WTS samples obtained from other water treatment plants were similar. In the present case of WTS, the wide band at $3638 \mathrm{~cm}^{-1}$ could be assigned to the stretching vibration of $\mathrm{O}-\mathrm{H}$ bonds while absorption band at $1634 \mathrm{~cm}^{-1}$ represents the bending vibration of $\mathrm{H}-\mathrm{O}-\mathrm{H}$ in water molecules chemically associated with $\mathrm{Al}(\mathrm{OH})_{3}$. The stretching vibrations generated by the $\mathrm{C}-\mathrm{O}$ groups in the carbonate appeared at around $431 \mathrm{~cm}^{-1}$. This represented the carbonate associated with other metals present in WTS as impurities in river water. The bands at 1146, 1038 and 789 $\mathrm{cm}^{-1}$ correspond to the stretching vibrations of $\mathrm{Si}-\mathrm{O}-\mathrm{Si}$ in the quartz while bending vibration of O-Si-O appeared at
$470 \mathrm{~cm}^{-1}$ in WTS This corresponds to major constituent of silica in WTS.

\subsection{Acidification of WTS}

Acidification of WTS was carried out by $\mathrm{H}_{2} \mathrm{SO}_{4}$ to releases the aluminum and iron from the sludge matrix which act as regenerated coagulating agent and used for removal of turbidity from water and wastewater. Such process of recovery of coagulants was studied earlier by acidification of sludge and applied in the wastewater treatment. Variable dosage of WTS acidified with different normality of $\mathrm{H}_{2} \mathrm{SO}_{4}$ wasusedto treat 1 liter of dairy waste water for turbidity removal. The results are plotted in Fig No 4 which showed that with increasing $\mathrm{H} 2 \mathrm{SO} 4$ normality from $1 \mathrm{~N}$ to $3 \mathrm{~N}$, the turbidity removal also increased.

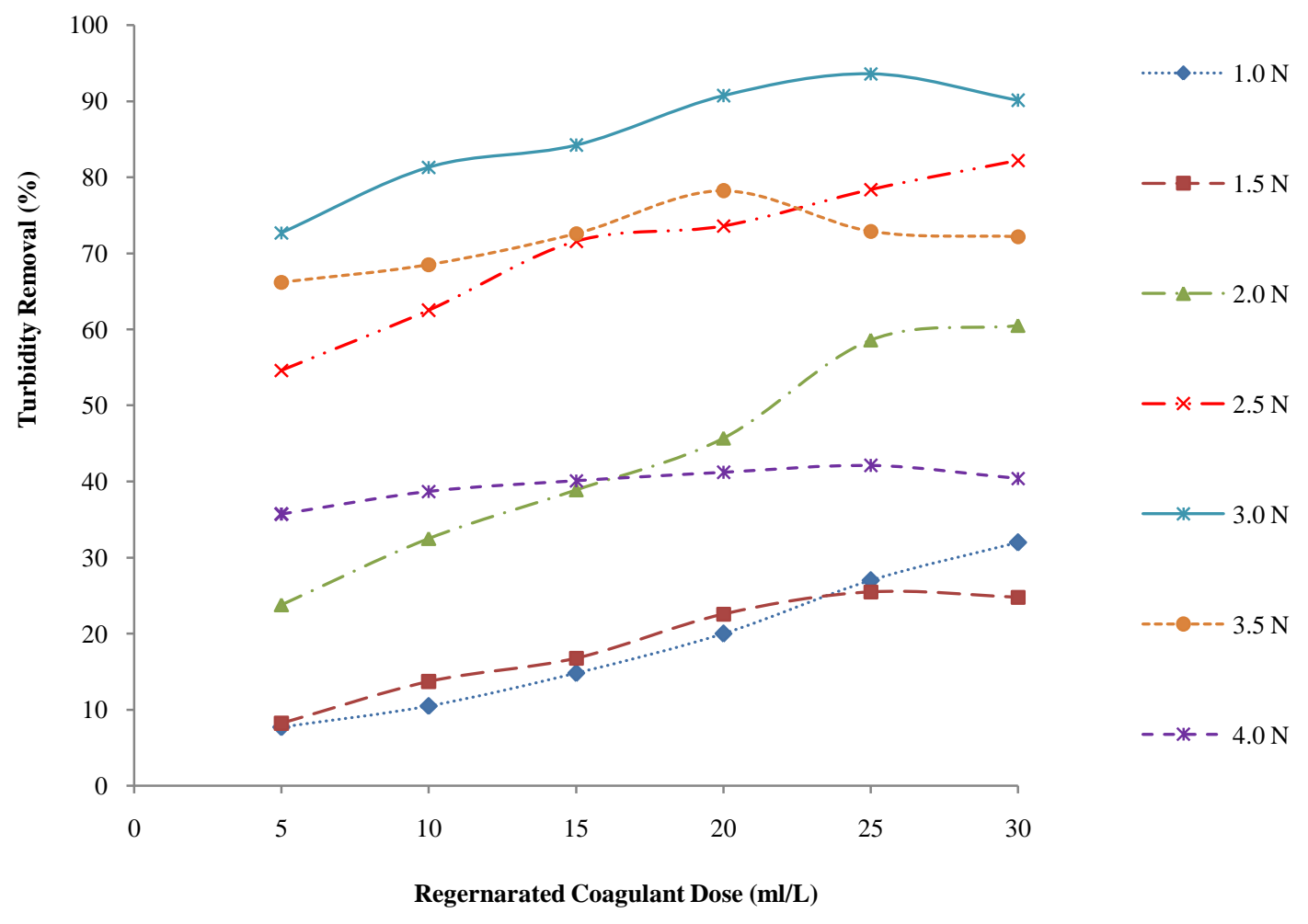

Fig 4: Turbidity removal with variable normality and different doses of regenerated coagulant from WTS

However, the turbidity of wastewater decreased when WTS was acidified with more than $3 \mathrm{~N} \mathrm{H}_{2} \mathrm{SO}_{4}$. The decreased in turbidity may be due to dissolution of Al- flocs at lower $\mathrm{pH}$ which adversely affected the coagulation process.Therefore, WTS acidification above $3 \mathrm{~N}$ of the medium was found less efficient in removing colloidal suspension from SDW (Fig No 4). The $3 \mathrm{~N}$ acidification of WTS with higher dose at 25 $\mathrm{ml}$ per liter SDW found as optimum condition showing a highest turbidity removal at $93.6 \%$. The trend of turbidity removal was high at all the dosage of $3 \mathrm{~N}$ acidified WTS (Fig No 4). At such an optimum conditions the Al-flocs relatively pre-dominant and adsorb more colloidal particle may be due to the availability of more adsorptive sites on aluminum hydroxide flocs. It provides good settle-ability of colloidal particles and reduces turbidity. Hence, it can be summarized from the present study that regenerated coagulant could be potential source to utilize and treat the wastewater. This reduces the volume of WTS and save the disposal cost and minimizes environmental and public health risk. 


\section{CONCLUSION}

Current practice of sludge disposal poses danger to the environment and community health. The reuse of WTS offers both economic and environmental sustainability. Prior characterizations of sludge in terms of its physic-chemical properties are necessary for better reuse and recycle as a safe disposal alternatives.

WTS application in water /wastewater treatment will provide some significant chemical savings through resource recovery, re-use, and sludge volume reduction. However, it is unlikely that the setup a wastewater treatment plant would close to a water treatment plants, but it could be a workable option overcoming long distances and high costs. Currently, the developing and many developed countries have introduced specific legislation related to the sound management WTS with focus on waste reduction and reuses guidelines. Ministry of Environment, New Delhi emphasized the need of waste minimization-waste reuse and recycling in the policy Statement for Abatement of pollution, 1992 and in E(P) Act 1986.

Regenerated coagulant recovered from WTS after $3 \mathrm{~N}$ $\mathrm{H} 2 \mathrm{SO} 4$ acidification and using its higher dose of $25 \mathrm{ml}$ per liter of dairy wastewaterperformed better, as compare to acidified sludge of other normality, and achieved maximum turbidity removal efficiency of $94 \%$ at neutral $\mathrm{pH}$ value. Hence, it can be concluded from the present study that regenerated coagulant could be possibly utilized to treat any wastewater. In particular, the reuse of water treatment sludge for treatment of dairy wastewater provides beneficial utilization and sustainable approach of WTS disposal.

\section{REFERENCES}

[1] Ahmad T, Ahmad K, Alam M., 2016a, Sustainable management of water treatment sludge through 3 'R'concept. J. Clean. Prod., 124: 1-13.

[2] Ahmad T, Ahmad K, Ahad A, Alam M., 2016b, Characterization of water treatment sludge and its reuse ascoagulant. J. Environ. Manage. 182: 606-611.

[3] American Public Health Association (APHA), American Water Works Association (AWWA), and Water Environmental Federation (WEF), 1998. In: Clesceri, L., Greenberg, A., Eaton, A. (Eds.), Standard Methods for the Examination of Water and Wastewater, 20th ed. American Public Health Association, Washington, DC.

[4] Amirtharajah, A, O'Melia, CR, 1990, Coagulation Processes: Destabilization, Mixing, and Flocculation, Water Quality and Treatment, 4th ed. McGraw Hill, New York, N.Y., pp. 269-371.

[5] Benjamin MM, 2002, Water Chemistry. McGraw Hill International Edition, pp. 644.

[6] Demirel B, Yenigun O, Onay TT, 2005, Anaerobic treatment of dairy wastewaters: A review. Process Biochem. 40: 2583-2595.
[7] Duan J, Gregory J., 2003 Coagulation by hydrolyzing metal salts. Adv. Colloid Interface Sci. 100-102: 475502.

[8] Guan X-H, Chen G-H, Shang C., 2005, Re-use of water treatment works sludge to enhance particulate pollutantremoval from sewage. Water Res. 39: 34333440

[9] Hamdani A, Chennaoui M, Assobhei O, MountadarM. , 2004, Dairy effluent characterization and treatment by coagulation decantation. Le Lait, 84 (3): 317-328.

[10] Herrington BL., 1948, Milk and Milk Processing. McGraw-Hill Book Company, Toronto.

[11] Karadag D, Köroglu OE, Ozkaya B, Cakmakci M, 2015, A review on anaerobic biofilm reactors for the treatment of dairy industry wastewater. Process Biochem. 50: 262-271.

[12] Kim JG, Kim JH, Moon H, Chon C, Ahn JS.,2002, Removal capacity of water plant alum sludge for phosphorus in aqueous solution. Chem. Spec. Bioavail. 14: 67-73.

[13] Kim S, Park N, Kim T, Park H.,2007, Re-aggregation of flocs in coagulation-cross-flow microfiltration. J. Environ. Eng. 133(5): 507-514.

[14] Kushwaha JP, Srivastava VC, Mall ID., 2011, An overview of various technologies for the treatment of dairy wastewaters. Crit. Rev. Food Sci. Nutr. 51: 442-52.

[15] Kushwaha JP, Srivastava VC, Mall ID, 2010a, Treatment of dairy wastewater by commercial activated carbonand bagasse fly ash: Parametric, kinetic and equilibrium modelling, disposal studies. Bioresour. Technol. 101: 3474-3483.

[16] Kushwaha JP, Srivastava VC, Mall ID, $2010 \mathrm{~b}$. Organics removal from dairy wastewater by electrochemicaltreatment and residue disposal. Sep. Purif. Technol. 76: 198-205.

[17] Kushwaha JP, Srivastava VC, Mall ID, 2010c, Treatment of dairy wastewater by inorganic coagulants: Parametric and disposal studies. Water Res. 44, 5867-5874.

[18] Lee, JD, Lee SH, Jo MH, Park PK, Lee JH, Kwak JW, 2000, Effect of coagulation conditions on membranefiltration characteristics in coagulationmico-filtration process for water treatment, Environ. Sci. Technol. 34: 3780-3788.

[19] Nair AT, Ahammed MM, 2015, The reuse of water treatment sludge as a coagulant for post-treatment ofUASB reactor treating urban wastewater. J. Clean. Prod. 96: 272-281.

[20] P.R. Gupta, Dairy India, 5th ed., 1997,National Dairy Development Board, Anand.

[21] Qasim W, Mane AV, 2013, Characterization and treatment of selected food industrial effluents bycoagulation and adsorption techniques, Water Resources and Industry 4: 1-12. 
[22] Ramasamy EV, Gajalakshmi S, Sanjeevi R, Jithesh MN, Abbasi SA, 2004, Feasibility studies on the treatment of dairy wastewaters with upflow anaerobic sludge blanket reactors. Bioresour. Technol. 93: 209212.

[23] Rao M, Bhole AG, 2002, Removal of organic matter from dairy industry wastewater using low-cost adsorbents. J. Indian Chem. Eng. Sect. A 44 (1): 2528.

[24] Rico Gutierrez J L, Garcia Encina PA, Fdz-Polanco F., 1991, Anaerobic treatment of cheeseproductionwastewater using a UASB reactor. Bioresour. Technol. 37: 271-276.

[25] Sarkar B, Chakrabarti PP, Vijaykumar A, Kale V, 2006, Wastewater treatment in dairy industries possibility of reuse. Desalination 195: 141-152.

[26] Selmer-Olsen E, Ratanweera HC, Pehrson R, 1996, A novel treatment process for dairy wastewater with chitosan produced from shrimp-shell waste. Water Sci. Technol. 11: 33-40.

[27] Sengil A, Ozacar M, 2006, Treatment of dairy wastewaters by electrocoagulation using mild steel electrodes. J. Hazard. Mater. 137: 1197-1205.

[28] Tchamango S, Nanseu-Njiki CP, Ngameni E, Hadjiev D, Darchen A, 2010, Treatment of dairy effluents by electrocoagulation using aluminium electrodes. Sci. Total Environ. 408: 947-952.

[29] Vourch M, Balannec B, Chaufer B, Dorange G, 2008, Treatment of dairy industry wastewater by reverseosmosis for water reuse. Desalination 219: 190-202.

[30] Xu GR, Yan ZC, Wang YC, Wang N, 2009, Recycle of Alum recovered from water treatment sludge in chemically

[31] HWMR, 2008, Hazardous Waste (management, handling and trans-boundary movement) Rules: Gazettes Notification, Sept. 24 , Environment Ministry. 